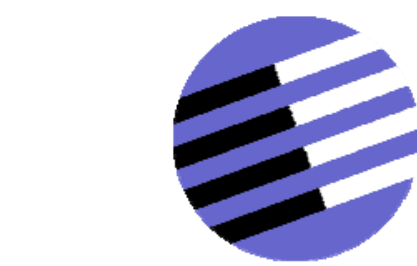

GOVERNANCE AND THE EFFICIENCY

OF ECONOMIC SYSTEMS

GESY

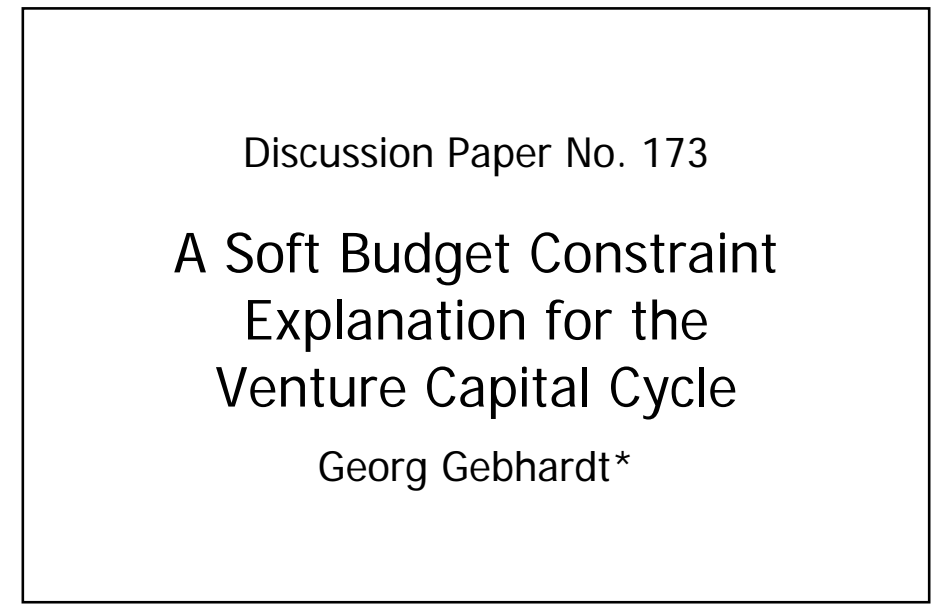

October 2006

*Georg Gebhardt, Department of Economics, University of Munich, Ludwigstr. 28 (Rgb.), D-80539 Munich.

Tel.: +49 892180 2876, Georg.Gebhardt@LRZ.uni-muenchen.de

Financial support from the Deutsche Forschungsgemeinschaft through SFB/TR 15 is gratefully acknowledged.

Sonderforschungsbereich/Transregio $15 \cdot$ www.gesy.uni-mannheim.de 


\title{
A Soft Budget Constraint Explanation for the Venture Capital Cycle
}

\author{
Georg Gebhardt \\ University of Munich*
}

October 2006

\begin{abstract}
We explore why venture capital funds limit the amount of capital they raise and do not reinvest the proceeds. This structure is puzzling because it leads to a succession of several funds financing each new venture which multiplies the well known agency problems. We argue that an inside investor cannot provide a hard budget constraint while a less well informed outsider can. Therefore, the venture capitalist delegates the continuation decision to the outsider by ex ante restricting the amount of capital he has under management. The soft budget constraint problem becomes the more important the higher the entrepreneur's private benefits are and the higher the probability of failure of a project is.
\end{abstract}

Keywords: Contract Theory, Corporate Finance, Venture Capital JEL-Classification: G24, G31, D82

*Department of Economics, University of Munich, Ludwigstr. 28 (Rgb.), D-80539 Munich, Tel.: +49 892180 2876, e-mail: Georg.Gebhardt@LRZ.uni-muenchen.de. I have benefitted a lot from many discussions with Klaus Schmidt. I would like to thank Matthew Bidwell, Sven Rady, Ferdinand von Siemens, Achim Wambach. Financial support by Deutsche Forschungsgemeinschaft through SFB/TR 15 is gratefully acknowledged. 
"We had to push our device over one major technical hurdle (...). I estimated it would take $\$ 8$ million. When I was told we had $\$ 2$ million and no more, I thought we were finished. (...) In the end, we did it for $\$ 2$ million (...). Looking back, if we had the $\$ 8$ million I might never have gotten our engineers to drop their pet projects to ensure the success of our principal product." 1

The above quote highlights that practitioners are well aware of the positive incentive effects a hard budget constraint has on start-up entrepreneurs. This paper develops a model that formalizes this intuition. We show that a well informed investor may ex post have an incentive not to liquidate an unsuccessful venture although ex ante he would like to commit to doing so. By raising only a limited amount of capital in the form of a venture capital fund the investor can effectively delegate the continuation decision to new investors, who - due to their lack of inside information - will terminate all unsuccessful projects.

A large literature has analyzed different aspects of the organization of venture capital funds: compensation schemes (Gompers and Lerner 1999a), the use of covenants (Gompers and Lerner 1996, Hellmann 1998), staged financing (Gompers 1995, Neher 1999) and convertible securities (Berglöf 1994, Schmidt 2003, Cornelli and Yosha 2003). However, the way venture capital funds restrict their access to capital after an initial amount has been raised has attracted scant

\footnotetext{
${ }^{1}$ Clayton, Gambill, and Harned (1999) p.51.
} 
attention in the literature. The amount of equity that is raised is limited and cannot be increased later. Moreover, venture capital contracts do not allow the fund to reinvest profits or issue debt. ${ }^{2}$ These restrictions enforce the so called "venture capital cycle" ${ }^{3}$ during which capital is first raised, then invested and, finally after some time, returned to the investors together with some interest. This process distinguishes venture capitalists from other intermediaries such as banks who raise, invest and return capital simultaneously.

After capital has been raised most of it is invested immediately in several firms so that the venture capital fund is unlikely to have enough capital to finance all its portfolio firms until an IPO or tradesale. This gives rise to syndication, i.e. co-financing of later rounds by new venture capitalists. ${ }^{4}$

This practice is puzzling given that the relationship between the different venture capitalists should suffer from similar asymmetric information problems as the relationship between investors and entrepreneurs. These problems are known to be severe. What is the advantage of limiting the capital available to venture capitalists if this limitation leads to a multiplication of contracting problems that could be avoided by giving more capital to the intermediary in the first place?

\footnotetext{
${ }^{2}$ See Gompers and Lerner (1999b), p.38-39.

${ }^{3}$ This term was coined by Gompers and Lerner (1999b).

${ }^{4}$ Lerner (1994) reports that on average 2.2 new investors enter in the second round of financing and 2 in later ones. 0.7 first round investors do not reinvest in the second round, and 0.9 investors of earlier rounds do not reinvest in each subsequent round (see p. 20).
} 
The answer we give in this paper is that the lack of capital of the original investor forces the entrepreneur to find new investors. The fact that these investors are less well informed than the original investor is shown to be advantageous because it provides a hard budget constraint for the entrepreneur which increases her ex ante incentives to exert effort. In the following, we will briefly outline the intuition for our main result.

Consider a wealth constrained entrepreneur who obtains capital from an investor. The investor is only interested in monetary returns while the entrepreneur derives a private benefit from running the firm. The entrepreneur's effort is necessary for the success of the project but cannot be contracted upon.

The quality of the project is unknown to both parties ex ante. If capital and effort are supplied the quality can ex post be inferred from the realization of profits. Without effort all types of projects deliver low profits and nothing can be learned.

The original investor can observe the effort choice. If the profit realization is low although effort has been exerted he understands that the project is likely to be of bad quality and will not refinance the venture. If he observes that no effort has been exerted the investor still holds his a priori belief and it is optimal for him to refinance the project.

This creates a trade off for the entrepreneur when deciding whether to supply effort or not: On the one hand, by exerting effort she looses her private benefits in the next period if the project turns out to be a failure. On the other hand she 
gains because she avoids delaying the monetary payoff for a period if the project turns out to be a success. For a small net present value project the potential surplus accruing to the entrepreneur is small and the former effect dominates. In this case she will not exert effort. This is anticipated by the investor who will not be willing to finance the project although it would be efficient. This implies ventures financed by an investor who can reinvest may, indeed, experience periods in which they are not able to secure enough funding to go ahead.

Now suppose the original investor cannot refinance the project due to lack of capital and a new investor, who did not observe the effort choice, has to be convinced to invest capital. The new investor can pursue one of two possible pure strategies. The first is to always refinance projects which had a low profit realization. In this case the incentive for the entrepreneur not to exert effort disappears because the project will never be shut down. Therefore, all projects with low profit realizations must be bad quality projects with a negative expected net present value. This strategy cannot be an equilibrium because the new investor could always do better by not refinancing projects with low profit realizations.

The second possible strategy is never to refinance a project after a low profit outcome. Again, the incentive for the entrepreneur not to exert effort disappears because shirking leads to low profit for sure. Thus, all low profit projects must be bad ones and it is optimal for the new investor not to refinance. However in period one, the original investor anticipates that the entrepreneur will exert effort and is willing to finance even marginal projects. 
The soft budget constraint problem dates back at least to Kornai $(1979)^{5}$. Schmidt (1996) and Cremér (1995) discuss settings different from ours in which less information helps to harden the budget constraint. A effect similar to ours has been noted independently by Bergemann and Hege (2002) albeit in an asymmetric information environment and without relating it to the venture capital cycle.

Closely related to this paper is Dewatripont and Maskin (1995) who show that investors may profit from being able to commit not to refinance projects. They argue that there is a coordination problem and two types of equilibria. One in which all investors pool their endowments and form a few large banks and another one in which the investors remain small. They use this result to explain the coexistence of different financial systems in different countries such as the Anglo-Saxon and the German-Japanese ones.

We use a related model that allows us to explain the coexistence of large banks and small venture capitalists within a financial system, e.g. the AngloSaxon one. Moreover, we can characterize the kind of projects that are most likely to suffer from the soft budget constraint problem and have to be financed by small investors. We find that this characterization is broadly in line with anecdotal evidence.

Inderst and Muennich (2001) look at the same question that we consider and point out another advantage of limiting the amount of capital available to venture capitalists. They show that ex-post competition for additional capital by success-

\footnotetext{
${ }^{5}$ See Maskin (1999) for an overview over the literature on hard and soft budget constraints.
} 
ful projects can improve ex-ante incentives. We suggest that restricting capital for failed projects has a similar effect. Both effects are likely to be important in reality.

The rest of the paper is organized as follows. Section I introduces the model. In Section II two different intermediaries called venture capital funds (with limited capital) and banks (with unlimited capital) are compared. Section III discusses some assumptions and possible extensions of the model. Finally, Section IV concludes. Proofs are relegated to the appendix.

\section{The Model}

In this section we consider a model of the investment and learning process which leads either to a new business or to the abandonment of the project. We use this model to study the contracting problems that arise if the wealth constrained entrepreneur needs to obtain funding from an investor.

The project requires two types of inputs. First, it requires effort that can only be supplied by the entrepreneur. For simplicity, the entrepreneur has a binary choice whether to supply effort or not. Effort is assumed to be costless which allows us to focus on the soft budget constraint problem. ${ }^{6}$

\footnotetext{
${ }^{6}$ See Gebhardt (2001) for an extension with private costs of effort. This adds a standard moral hazard problem which is shown not to interact with the soft budget constraint question studied here.
} 
Most entrepreneurs tend to work very hard. However, many start-ups are founded by engineers or scientists who derive a private benefit from breakthroughs in research even if these are not commercially viable. Hence, they dislike spending time on tasks like marketing and investor relations and prefer to develop the product that is most interesting to them but not necessarily best to sell to customers. Thus, exerting effort for the founders means to "drop their pet projects to ensure the success of our principal product"7, as the entrepreneur quoted in the introduction put it.

An inside investor can detect if the entrepreneur neglects the investor's interests but it will be difficult to prove the misbehavior to outsiders like other investors or a court. This is modeled by making the effort choice observable to the investor who has supplied capital in the same period but not observable to potential new investors or courts. In fact, our assumption is that the investor must observe the effort choice even if he preferred not to do so, reflecting the fact that an investor who takes serious his role as an adviser cannot avoid noticing clues as to whether the entrepreneur pursues the investors best interests.

The second input is a capital investment $K$ which must be provided by an outside investor because the entrepreneur does not have any wealth. It is either supplied or not, which reflects the lumpy nature of investments in the early phase of a firm (e.g. laboratories or clinical trials).

In every period in which there is investment the entrepreneur receives a non

${ }^{7}$ Clayton, Gambill, and Harned (1999) p.51. 
transferable private benefit $b<K$. This captures the fact that founders are not only motivated by monetary incentives but also look for independence and have a missionary zeal for their innovation. If the project is successful ${ }^{8}$ there is a verifiable monetary payoff of $R$, which should be interpreted as the expected net present value of the cash flows generated by the business idea given that a milestone has been reached. Both payoffs, monetary and not monetary, are discounted by both players by the same discountfactor $\delta$.

Because success is meant to model events after which the firm continues to exist so that the entrepreneur does not lose her private benefits we assume that the entrepreneur gets a private benefit of $B$ in this case. An analytically convenient specification is to assume that the benefit is as high as it would be in the case of continued investment, i.e. $B=\frac{\delta b}{1-\delta}$. However, other specifications would not change the qualitative results as long as $B$ is a monotonic function of $b$.

The uncertainty involved in the implementation of a new business idea is captured by the assumption that there are good and bad projects and both the entrepreneur and the venture capitalist only know the prior probability $\lambda^{0}$ of the project being good.

The two types of projects differ with respect to their probabilities of success. Thus, each period in which both inputs are supplied results in a signal about

\footnotetext{
${ }^{8}$ Success can be any event that is observable by investors outside a specific venture capital relationship and that makes future success more likely, e.g. a patent, a working prototype or the acquisition of launch customers. Practitioners refer to these events as milestones.
} 
quality so that uncertainty is resolved over time in a learning by doing process. More precisely, in each period (subsequently denoted by $t$ ) in which both inputs are supplied the probability of success is $\gamma>0$ for the good project and zero for the bad project. If one of the inputs is missing the probability of success is zero independent of the type. This assumption is stronger than necessary and imposed for simplicity. For the results to go through it suffices that effort increases the probability of success.

If one of the inputs has not been supplied in a certain period nothing can be learned from a bad realization at the end of the period. In the following, we will call this event "no signal". If there has been investment and effort there is either success (also called a "good signal") and the game ends or failure (a "bad signal").

To formally describe the resolution of uncertainty we introduce the following notation. Let $\lambda_{t}$ denote the belief by the players $^{9}$ that the project is good at the beginning of period $t$. The possible values that $\lambda_{t}$ can take on are contained in a sequence indexed by superscript $k:\left\{\lambda^{k}\right\}_{0}^{\infty}$, where $\lambda^{k}$ is the belief that the project is good after both inputs have been supplied $k$-times without success. $\lambda^{k}$ evolves according to Bayes Rule:

$$
\lambda^{k+1}=\frac{\lambda^{k}(1-\gamma)}{1-\lambda^{k} \gamma}
$$

\footnotetext{
${ }^{9}$ For the moment we restrict ourselves to the case of symmetric information so that the beliefs are identical for all players. Later we will have to consider differing beliefs.
} 
Hence for any $k, \lambda^{k}$ can be written as a function of $\lambda^{0}$ :

$$
\lambda^{k}=\frac{\lambda^{0}(1-\gamma)^{k}}{1-\lambda^{0}+\lambda^{0}(1-\gamma)^{k}}
$$

If at the beginning of period $t$ the belief was $\lambda_{t}=\lambda^{k}$ and there is no signal in period $t$ because one of the inputs was missing then $\lambda_{t+1}=\lambda_{t}=\lambda^{k}$. If there was, however, a bad signal then $\lambda_{t+1}=\lambda^{k+1}$.

It is efficient to invest and exert effort as long as the project has a positive net present value, i.e as long as ${ }^{10}$

$$
\lambda_{t} \geq \lambda^{*}=\frac{K}{\gamma R}
$$

We can then implicitly define $k^{*}$ as the efficient number of trials by

$$
\lambda^{k^{*}} \geq \lambda^{*}>\lambda^{k^{*}+1}
$$

The game consists of $N=k^{*}+1$ periods. ${ }^{11}$ This finite horizon set-up is chosen not only for convenience. We are considering investments into new business models and technologies. In almost all these cases competitors are working on the same ideas or ideas that could serve as a substitute so that there is a limited window of opportunity for the venture. This aspect is better captured in a finite horizon model. However, the results do not depend on this assumption. In Section III we informally discuss an infinite horizon version in which we get qualitatively identical results.

\footnotetext{
${ }^{10}$ In this definition of the first best we are ignoring the private benefit $B$ because no contract could possibly extract that benefit from the wealth constrained entrepreneur.

${ }^{11}$ Any other finite horizon with $N>k^{*}$ periods, will lead to qualitatively the same results.
} 
Each period begins with the entrepreneur making a take-it-or-leave-it offer for a financing contract, which is subsequently either accepted or rejected. ${ }^{12}$ If it is rejected any existing contract remains valid. If no contract exists a null contract (no investment in all future periods) is assumed to be the default option. Then, investment takes place followed by the effort choice of the entrepreneur. At the end of the period the profit is realized. The following figure depicts the exact timing of one period of the game:

\begin{tabular}{ccccc}
1 & 2 & 3 & 4 & 5 \\
\hline & $\mid$ & investment & effort \\
$\begin{array}{c}\text { contract } \\
\text { offer }\end{array}$ & accept & $\begin{array}{c}\text { according } \\
\text { to contract } / \text { no }\end{array}$ & $\begin{array}{c}\text { is exerted } \\
\text { yes } / \text { no }\end{array}$ & $\begin{array}{c}\text { profits are } \\
\text { realized }\end{array}$
\end{tabular}

The equilibrium concept is Perfect Bayesian Equilibrium.

Let us specify the contracting environment in order to derive the set of all admissible financing contracts that may be offered by the entrepreneur. First of all, investment is observable by both parties and contractible. A contract offered in period $t$ may, therefore, specify an obligation for the investor to provide capital in period $t .^{13}$ In addition revenues $R$ are contractible so that a contract can lay down a sharing rule where $E_{t}$ is the payment to the entrepreneur if there is success in period $t .{ }^{14} I_{t}$ denotes the respective payment to the investor, i.e. $I_{t}=R-E_{t}$.

\footnotetext{
${ }^{12}$ This amounts to assuming that the entrepreneur has all the bargaining power. We discuss the impact of a change in the distribution of bargaining power in Section III.

${ }^{13}$ Allowing for contracts specifying random investments does not change the results while complicating the exposition.

${ }^{14}$ That does not necessarily mean that the occurrence of success is contractible. One should
} 
Because the effort choice cannot be observed by outsiders it is not contractible.

The fact that we only consider one period contracts may seem highly restrictive, however, once we have established our main results we can show with a simple argument that allowing any kind of long term contract does not change the qualitative results. We present that argument in Section III.

We compare two types of intermediaries called "bank" and "venture capitalist". ${ }^{15}$ As will become clear later most other forms of financing e.g. business angels, internal capital markets or corporate venture capital can be subsumed under one of these types. While there are many characteristics distinguishing these intermediaries we will concentrate on the amount of capital available to them.

The bank type is an intermediary that has enough capital to finance any number of investment rounds without resorting to outside investors to supply it with additional funds. ${ }^{16}$ The venture capitalist has only a limited amount of capital so that he can finance only one round of investment. Hence, other venture think of the sharing rule as shares of equity held by the investor and the entrepreneur respectively.

${ }^{15}$ We do not consider direct financing via capital markets as start-ups are usually too small to have access to it. Moreover, it is well established that intermediaries provide countless valuable services such as advice, executive search and monitoring. See e.g. Gompers (1995) or Sahlman (1990).

${ }^{16}$ Apart from banks this category could also include internal capital markets in mature firms with free cash flow. 
capital funds have to be found to take over financing the portfolio company so that the continuation decision is delegated to the new venture capitalists. ${ }^{17} \mathrm{~A}$ convenient way to introduce this distinction into our model is to model the bank as a single player that can observe the effort choice of the entrepreneur and the venture capital fund as a single player that cannot observe the effort choice.

\section{Venture Capital Funds and Banks}

We can now use the model to compare the different types of investors and determine why venture capitalists do better than banks when it comes to financing innovations.

We first look at a bank, i.e. an investor who has observed past effort choices. We can calculate the equilibrium by backward induction. Suppose the game has arrived in the ultimate period $(N)$ and at least one more trial would be efficient $\left(k<k^{*}\right)$. Then the unique continuation equilibrium is for the entrepreneur to propose a share $I_{N}=\frac{K}{\gamma \lambda_{N}}$ to the investor, who accepts it and exerts effort. High effort is optimal for the entrepreneur because otherwise she would forgo a positive probability to get her share in the monetary return (and the private benefit $B$ ). The share $\left(I_{N}\right)$ makes the bank just break-even given the entrepreneur's effort choice and is, therefore, the lowest share accepted by the investor. A similar

\footnotetext{
${ }^{17}$ We will relax the assumption that a venture capital fund has just enough capital to fund a firm only once in Section III.
} 
argument can be made for any period in which the number of additional trials that would be efficient is larger than the number of remaining periods. In these cases the continuation equilibria implement the efficient investment and effort choices and the entrepreneur gets the whole surplus.

Suppose, however, the game has arrived in the penultimate period $(N-1)$ and only one further trial is efficient $\left(\lambda_{N-1}=\lambda^{k^{*}}\right)$. Now it is no longer sure that the efficient investment and effort decisions take place. To see why, assume the entrepreneur has proposed $I_{N-1} \geq \frac{K}{\gamma \lambda_{N-1}}$ and the investor has accepted. If the entrepreneur now does exert effort the game ends for sure either because the project is successful or because $\lambda_{N}<\lambda^{*}$ and it is no longer efficient to try out the new business. If she does not exert effort the game moves into the last period and the efficient choice is implemented.

In the latter case the expected payoff to the entrepreneur is

$$
\Pi^{N E}=b+\delta\left[b+\gamma \lambda^{k^{*}}(R+B)-K\right]
$$

while in the former it is

$$
\Pi^{E}=b+\gamma \lambda^{k^{*}}(R+B)-K
$$

Subtracting the equations from each other we get the following condition that must hold so that it is optimal for the entrepreneur to exert effort given the above contract:

$$
\Pi^{E} \geq \Pi^{N E} \Leftrightarrow\left(1-\gamma \lambda^{k^{*}}\right) \delta b \leq(1-\delta)\left[\gamma \lambda^{k^{*}} R-K\right]
$$


The advantage of shirking is that the entrepreneur can enjoy an additional period of the private benefit in case the project ultimately fails, the cost is that the potential monetary payoff is delayed by one period. If the private benefit is large or the expected surplus is low, delaying the project may be profitable for the entrepreneur. In this case the investor will not be willing to finance the project in the first place and the entrepreneur faces a financing crisis.

It can be shown by backward induction that if the entrepreneur does not have an incentive in the last period to shirk she does not have one in the earlier periods, either. Intuitively a higher belief $\lambda$ decreases the probability of failure and delays its occurrence and, therefore, decreases the value of an additional $b$ in this case. In addition it means that there are more efficient trials left which increases the the net present value that is delayed and, therefore, the cost of shirking. More formally in period $t$ with belief $\lambda_{t}=\lambda^{k}, k<k^{*}$ the condition for not exerting effort is given by ${ }^{18}$

$$
b \leq \frac{(1-\delta)\left\{\frac{1-[\delta(1-\gamma)]^{k^{*}-k}}{1-\delta(1-\gamma)} \lambda^{k}(\gamma R-K)-\frac{1-\delta^{k^{*}-k}}{1-\delta}\left(1-\lambda^{k}\right) K\right\}}{\left[1-\lambda^{k}+\lambda^{k}(1-\gamma)^{k^{*}-k}\right] \delta^{k^{*}-k}}
$$

It remains to characterize equilibrium play if (3) is violated. Because there are $k^{*}+1$ periods the project cannot be delayed more than once. However, if (3) is violated it must be delayed at least once. Thus we know that in equilibrium there will be investment and effort in $N-1$ periods and neither investment nor

\footnotetext{
${ }^{18}$ See the proof of proposition 1 in the appendix for the backward induction argument, the derivation of condition 4 and a formal argument why (4) always holds if (3) holds.
} 
effort in one period.

The exact timing of the delay can be determined by working backwards. Suppose (3) is violated and in $N-2$ there are still two efficient trials to go, i.e. there has not been delay so far. Independent of the equilibrium play in period $N-2$ the ultimate trial will take place in the last period. Either the penultimate trial is delayed to period $N-1$, in this case the ultimate trial can only take place in period $N$, or the penultimate trial is not delayed, then we are back in the situation we analyzed above and because (3) is violated the last trial will be delayed to period $N$.

Then the decision problem for the entrepreneur, whether to exert effort or not given that investment has taken place, looks exactly like it did in the case of the ultimate trial only that the belief now is $\lambda^{k^{*}-1}$. The entrepreneur will exert effort given a contract that gives her the whole surplus if

$$
\left(1-\gamma \lambda^{k^{*}-1}\right) \delta b \leq(1-\delta)\left[\gamma \lambda^{k^{*}-1} R-K\right]
$$

In this case the investor will accept the financing contract if (5) is violated he will not do so in the first place and the projects stops for one period and is completed in the last two periods.

Equilibrium play if (3) is violated can then be found by the following algorithm. If (5) holds the project will be delayed exactly in period $N-1$. If it does not hold we have to work backwards to find the first period in which $\lambda_{t}$ is large 
enough so that the project will not be delayed, i.e.

$$
\left(1-\gamma \lambda_{t}\right) \delta b \leq(1-\delta)\left[\gamma \lambda_{t} R-K\right]
$$

If we can find one the delay happens in period $t+1$, if we cannot it happens in period one. Note that the less often the project has been undertaken the larger is $\lambda_{t}$ and the larger is the cost of delay and the smaller is the gain. Hence, for the first trials the incentive not to exert effort may disappear. ${ }^{19}$

Note that, so far, we have not proved that 6 ensures that the entrepreneur will always have an incentive to work hard in periods before $t$. We leave this to the proof of proposition 1 in the appendix. Proposition 1 summarizes the main results:

Proposition 1 With bank financing projects are inefficiently delayed in equilibrium if and only if

$$
b>\frac{1-\delta}{\left(1-\gamma \lambda^{k^{*}}\right) \delta}\left(\gamma \lambda^{k^{*}} R-K\right)
$$

Proof. See Appendix.

Let us contrast this result with financing by a venture capitalist who does not have enough funds to finance a second round of investment and who, therefore, has to find another venture capital fund to provide capital in subsequent periods. This new investor has not observed the effort choices of the entrepreneur so far and will base his decision only on the publicly available information, i.e. how

\footnotetext{
${ }^{19}$ Allowing more periods can lead to multiple and longer spells of delay, however, the condition for no delay remains the same.
} 
often there has been investment and whether the project has been successful so far or not.

Let us again work backwards from the last period. There the entrepreneur again never has an incentive to shirk because delay is impossible. Hence, there is always a financing contract that a new venture capitalist accepts as long as the new venture capitalist holds a belief larger than $\lambda^{*}$. Note that this belief cannot depend on the actual effort choices of the entrepreneur in earlier periods but only on expected equilibrium play.

The entrepreneur anticipates this, when deciding whether to supply effort or not in the penultimate period. She understands that failed projects are either always or never refinanced in the last period. If failed projects are never refinanced in the last period any kind of failure, be it due to lack of effort or not, is punished with termination. Thus, she will always exert effort because this increases the probability of success. If her project is always refinanced in the last period failure is never punished by termination and the incentive not to exert effort disappears, too.

Hence, it is a dominant strategy for the entrepreneur to exert effort in the penultimate period if her offer has been accepted by a venture capitalist. Anticipating this a new venture capitalist will be willing to supply capital in exchange for a share in $R$ that makes him just break even in expectation. The same argument holds for all previous periods so that the equilibrium beliefs of the entering venture capitalists must be that the entrepreneur has always exerted effort if 
capital has been invested. From that follows that there will be venture capitalists willing to supply capital for exactly $k^{*}$ trials so that the first best is always implemented. The following proposition formalizes this intuition:

Proposition 2 With venture capital finance the first best is always implemented.

\section{Proof. See Appendix.}

Intuitively, projects with a high probability of failure but the same expected net present value should suffer more from the soft budget constraint problem because the incentive not to exert effort even though it is costless is derived from the benefit of another round of investment in the case of failure. This benefit goes up if the probability of failure goes up.

To formalize this intuition we introduce a sequence of projects that have the same initial probability $\lambda^{0}$ to be of good quality and the same net present value conditional on being good $V=\gamma R$. They differ, however, with respect to their $\gamma$ and $R$. More precisely, we start with a project with some $\gamma$ and $R$, and therefore a certain $V$. Along the sequence we decrease $\gamma$ and adjust $R$ according to $R=\frac{V}{\gamma}$, i.e we increase $R$ so that $V$ stays constant.

Considering condition 5 we can calculate for each project in the sequence a threshold value $\hat{\lambda}$ so that there is delay if the belief drops below that value. $\hat{\lambda}$ is implicitly defined by

$$
(1-\gamma \hat{\lambda}) \delta b=(1-\delta)[\hat{\lambda} V-K]
$$


The larger $\hat{\lambda}$ the more a project suffers from the soft budget constraint problem. Increasing risk by decreasing $\gamma$ while holding $V$ constant increases $\hat{\lambda}$ which confirms our intuition that riskier projects suffer more from the soft budget constraint problem.

Proposition 3 sums up this comparative statics result.

Proposition 3 Consider a sequence of projects indexed by subscript $p$ with the same $\lambda_{p}^{0}=\bar{\lambda}^{0}$ and $V_{p}=\gamma_{p} R_{p}=\bar{V}$, but decreasing (increasing) values of $\gamma_{p}\left(R_{p}\right)$. Then the threshold value for the belief $\hat{\lambda}_{p}\left(\gamma_{p}\right)$ below which there is delay is falling in $\gamma_{p}$.

\section{Extensions and Discussion}

The qualitative results do not depend on the finite horizon set-up. In an infinite horizon model one can show that in each case (banking and venture capital) there is a unique Markov Perfect Bayesian Equilibrium (MPBE) properties similar to the properties of the respective equilibria in the finite horizon case. Here we just give an informal argument.

Consider a game in which each period is identical to the game under bank financing but where there is an infinite number of periods. Note that in this game all payoff relevant information is summarized by the belief $\lambda_{t}$, which we call the state of the game. In a MPBE strategies can only be conditioned on the payoff relevant components of the history. Hence, whenever the game is in a certain 
state the ensuing equilibrium play has to be the same. As in the finite horizon game we are interested in the condition that has to hold so that the first best is achieved in the bank case.

Suppose equilibrium play is efficient, i.e. there is investment and effort whenever the game is in a state $\lambda_{t} \geq \lambda^{k^{*}}$ and there is neither in every state $\lambda_{t}<\lambda^{k^{*}+1}$. For this to be an equilibrium it is a necessary condition that it is optimal for the entrepreneur to exert effort when the state $\lambda_{t}=\lambda^{k^{*}}$ and the contract in place prescribes investment in exchange for $I_{t}=\frac{K}{\gamma \lambda^{k^{*}}}$.

In this situation, if the entrepreneur exerts effort, there is either success or the game moves on to state $\lambda^{k^{*}+1}$ with no future investment. This results in an expected payoff of $b+\gamma \lambda^{k^{*}}(R+B)-K$ to the entrepreneur. By deviating to no effort the entrepreneur makes success in $t$ impossible and keeps the game in state $\lambda^{k^{*}}$ so that the first best is implemented in period $t+1$. The expected payoff is then $b+\delta\left[b+\gamma \lambda^{k^{*}}(R+B)-K\right]$. Comparing the two expected payoffs results in exactly the same condition 3 as in the finite horizon game. If it is fulfilled exerting effort is optimal and the first best is indeed an equilibrium. By the same arguments as in the finite horizon game we can show that if there is no delay at $\lambda^{*}$, there is none for higher $\lambda^{\prime}$ 's so that inequality 3 is not only a necessary but also a sufficient condition for the first-best to be reached.

If this condition is violated, however, the game drops into an inefficient mixed strategy continuation equilibrium with random delay. The entrepreneur offers $I=$ $R$ to the bank and exerts effort with a low enough probability so that the investor 
is just indifferent between accepting and rejecting the offer. If the entrepreneur has not exerted effort the bank refinances with a low enough probability to make the entrepreneur just indifferent between effort and no effort.

In the case of bank financing it can be shown by the same arguments as in the finite horizon game that the first-best is the unique MPBE for all parameters.

The assumption that the entrepreneur has all the bargaining power in all periods deserves further discussion. First, note that a simultaneous reduction of the entrepreneur's bargaining power in all periods reduces the surplus available to the entrepreneur. This implies a reduction of the cost of delay and exacerbates the soft budget constraint problem.

However, more of a problem could be the case of changing bargaining power during the course of the game. Off the equilibrium path only the investor involved in the project has observed the effort choice and has, therefore, a higher belief $\lambda$ than other investors. Being the only available investor he should be able to negotiate a higher share in the surplus than on the equilibrium path where he had to compete with many other investors.

Consider parameters so that with constant bargaining power there would be delay in period $N-1$, if there was not any before. Can delay be avoided with changing bargaining power? By exerting effort in period $N-1$ the entrepreneur still gets $b+\gamma \lambda^{k^{*}}(R+B)-K$. But if she delays all other banks will believe the project is bad and will not refinance only the bank that has observed the effort choice is left. Let us make the most extreme assumption that this bank 
can extract all the monetary payoff. Then by delaying the entrepreneur gets only $b+\delta\left(b+\gamma \lambda^{k^{*}} B-K\right)$. Rearranging yields the following condition for effort to be supplied

$$
\left(1-\gamma \lambda^{k^{*}}\right) \delta b \leq\left[\gamma \lambda^{k^{*}} R-K\right]
$$

This condition is less strict than (3) but still not the first best. The soft budget constraint problem does not disappear for projects with small enough surplus in the last period and large enough private benefits. Again this argument holds even stronger for projects that with constant bargaining power would experience delay in an earlier period than $N-1$.

So far, we have also neglected long-term contracts. First, note that whenever a contract leading to an outcome that is less efficient than the one with one period contracts is in place at the beginning of a period it will be renegotiated. This implies especially that after the project has been delayed once, the first best is implemented. In this case there is always the benefit $b$ to the entrepreneur, which cannot be extracted by the investor due to the wealth constraint.

The maximum a long-term contract can do is to transfer as much of the monetary surplus to the investor in case the project is delayed. This could be achieved by a first period contract that gives the investor an option to reinvest in exchange for $R$ in period $N$. Effectively, this contract shifts all the bargaining power in period $N$ to the investor. However, as we have seen this mitigates the incentive to delay but is not enough to eliminate the inefficiency. 
Another assumption was that the venture capitalist can never refinance a portfolio company. Again, this assumption is not necessary for the result. To see this we introduce a probability $\rho$ that the venture capitalist has some capital left into equation 7 . In this case it reads as follows:

$$
b>\frac{(1-\rho \delta)\left(\gamma \lambda^{k^{*}} R-K\right)}{\left(1-\frac{1-\rho \delta}{1-\delta} \gamma \lambda^{k^{*}}\right) \rho \delta} .
$$

If $\rho=1$ we are back in the bank case. If $\rho$ is reduced, however, the threshold value of $b$ increases and it goes to infinity as the probability to have some capital left goes to zero. Hence, as long as $\rho$ is less than one there is a gain from hardening the budget constraint through the venture capital cycle, i.e. there are projects which are delayed with bank financing but not with venture capital financing.

\section{Conclusion}

We have shown that projects which have a high probability of failure and offer a high private benefit to the entrepreneur will profit most from the hard budget constraint venture capital financing provides. And, indeed, the innovative projects normally financed by venture capitalists are characterized by these two features. How large the efficiency advantage of venture capital financing can be is demonstrated by Clayton, Gambill, and Harned (1999) in their case study of the development of hand-held organizers:

In the early nineties Palm Computing and Apple roughly simultaneously developed palm-sized computers. Both were initially not successful with cus- 
tomers. While venture capital financed Palm Computing was forced to dramatically change the design of its organizer in a way that made it simpler and cheaper Apple only reacted with small modifications. In the end Palm Computing took the market having spent only $\$ 8$ million on the development while Apple ended its efforts unsuccessfully after devoting more than $\$ 500$ million to it. ${ }^{20}$

${ }^{20}$ See Clayton, Gambill, and Harned (1999) p.48. 


\section{Appendix}

\section{Proof of Proposition 1}

Consider the subgame in which the game is in the last period $(N)$ and the belief is $\lambda^{k^{*}}$. Suppose at time four in this period investment has been provided and some contract with a share $E_{N} \geq 0$ for the entrepreneur is in place. Then it is optimal for the entrepreneur to exert effort because it is costless and she gets a nonnegative monetary payoff in case of success.

At time two the investor will accept any contract which makes him break even given that he expects effort to be supplied and given his belief $\lambda^{k^{*}}$. He will accept any contract as long as

$$
I_{N} \geq \hat{I}=\frac{K}{\gamma \lambda^{k^{*}}}
$$

In this case the entrepreneur will offer the lowest possible share $I_{N}=\hat{I}$ at time one.

If the bank enters the last period with a belief $\lambda<\lambda^{*}$ there is no contract that allows the entrepreneur to break even and no investment will take place.

Now consider the subgame in which the game is in period $N-1$ and both players hold the belief $\lambda^{k^{*}}$, i.e. so far there has not been delay. Suppose at time one a contract with $\hat{I}$ has been proposed and accepted and the entrepreneur has to decide whether to exert effort or not. If she chooses high effort the project will not be financed in period $N$ and the period $N$ payoff will be zero. Therefore, the 
expected payoff from supplying effort is

$$
\Pi^{E}=b+\gamma \lambda^{*}(R+B)-K
$$

If she does not exert effort by the above argument the project will receive financing in period $N$ and the expected period $N$ payoff will be $b+\gamma \lambda^{*}(R+B)-K$. Thus the expected payoff of no effort in period $N-1$ is

$$
\Pi^{N E}=b+\delta b+\delta\left(\gamma \lambda^{*}(R+B)-K\right)
$$

Condition 7 follows from comparing these two expected payoffs and solving for $b$. If condition 7 holds it is better for the entrepreneur not to exert effort. Because this holds even stronger for any contract offering an $I>\hat{I}$ there is no period $N-1$ contract acceptable to the investor which can elicit effort and no investment will take place.

If condition 7 does not hold, a contract with $\hat{I}$ does induce effort. Therefore, it will be accepted by the investor. Because it is the contract with the lowest share for the investor that is still accepted by the investor the entrepreneur will propose it in equilibrium. We can conclude that there will be no delay in period $N-1$ if there has not been delay before and if condition 7 does not hold.

To prove that there will be no delay in earlier periods if there is no delay in period $N-1$ the following expressions will be useful. Suppose the game is at the beginning of period $t$ and the belief $\lambda_{t}=\lambda^{k}$. Further suppose that there will be no delay in the continuation equilibrium starting with period $t$, that there are enough periods to undertake $k^{*}$ trials and that the entrepreneur captures the 
whole surplus. Then the expected monetary payoff for the entrepreneur is given by

$M^{k}=\gamma \lambda^{k}\left(R-\frac{K}{\gamma \lambda^{k}}\right)+\delta(1-\gamma) \gamma \lambda^{k}\left(R-\frac{K}{\gamma \lambda^{k+1}}\right)+\cdots+\delta^{k^{*}-k}(1-\gamma)^{k^{*}-k} \gamma \lambda^{k}\left(R-\frac{K}{\gamma \lambda^{k^{*}}}\right)$

Using the updating relationship in equation 2

$$
\begin{aligned}
M^{k}= & \gamma \lambda^{k} R-K+\delta(1-\gamma) \gamma \lambda^{k} R-\delta\left[1-\lambda^{k}+\lambda^{k}(1-\gamma)\right] K+\cdots+ \\
& +\delta^{k^{*}-k}(1-\gamma)^{k^{*}-k} \gamma \lambda^{k} R-\left[1-\lambda^{k}+\lambda^{k}(1-\gamma)^{k^{*}-k}\right] K \\
= & \frac{1-[\delta(1-\gamma)]^{k^{*}-k+1}}{1-\delta(1-\gamma)} \lambda^{k}(\gamma R-K)-\frac{1-\delta^{k^{*}-k+1}}{1-\delta}\left(1-\lambda^{k}\right) K
\end{aligned}
$$

Note that $M^{k}>M^{k^{\prime}}$ if $k^{\prime}>k$.

Similarly, we can write the expected value of the private benefits in period $t$ with the belief $\lambda^{k}$ under the identical assumptions as above as

$$
\begin{aligned}
B^{k}= & b+\gamma \lambda^{k} \frac{\delta b}{1-\delta}+\left[1-\lambda^{k}+\lambda^{k}(1-\gamma)\right] \delta b+\lambda^{k}(1-\gamma) \gamma \frac{\delta^{2} b}{1-\delta}+\cdots+ \\
& +\left[1-\lambda^{k}+\lambda^{k}(1-\gamma)^{k^{*}-k}\right] \delta^{k^{*}-k} b+\gamma \lambda^{k}(1-\gamma)^{k^{*}-k} \frac{\delta^{k^{*}-k+1} b}{1-\delta} \\
= & \gamma \lambda^{k} \frac{b}{1-\delta}+\gamma \lambda^{k}(1-\gamma) \frac{b}{1-\delta}+\cdots+\gamma \lambda^{k}(1-\gamma)^{k^{*}-k} \frac{b}{1-\delta}+ \\
& +\left[1-\lambda^{k}+\lambda^{k}(1-\gamma)^{k^{*}-k+1}\right]\left(b+\delta b+\cdots+\delta^{k^{*}-k} b\right) \\
= & \gamma \lambda^{k} \frac{1-(1-\gamma)^{k^{*}-k+1}}{1-(1-\gamma)} \frac{b}{1-\delta}+\left[1-\lambda^{k}+\lambda^{k}(1-\gamma)^{k^{*}-k+1}\right] \frac{1-\delta^{k^{*}-k+1}}{1-\delta} b \\
= & {\left[1-\delta^{k^{*}-k+1}+\left(\lambda^{k}-\lambda^{k}(1-\gamma)^{k^{*}-k+1}\right) \delta^{k^{*}-k+1}\right] \frac{b}{1-\delta} }
\end{aligned}
$$

Again note that $B^{k}>B^{k^{\prime}}$ if $k^{\prime}>k$.

Suppose the parameters violate condition 7 and consider the subgame in which the game is in period $N-2$ and both players hold the belief $\lambda^{k^{*}-1}$, i.e. so far 
there has not been delay. Suppose at time one a contract with $I_{N-2}=\frac{K}{\gamma \lambda^{k^{*}-1}}$ has been proposed and accepted and the entrepreneur has to decide whether to exert effort or not. From a backwards induction argument follows that if she exerts effort her expected payoff will be $M^{k^{*}-1}+B^{k^{*}-1}$, if she does not it will be $b+\delta\left(M^{k^{*}-1}+B^{k^{*}-1}\right)$. Hence, she will exert effort if

$$
b-(1-\delta) B^{k^{*}-1} \leq(1-\delta) M^{k^{*}-1}
$$

Solving for $b$ on the left hand side we get

$$
\left[1-\gamma \lambda^{k^{*}-1}(2-\gamma)\right] \delta^{2} b \leq(1-\delta)\left\{\frac{1-[\delta(1-\gamma)]^{2}}{1-\delta(1-\gamma)} \lambda^{k^{*}-1}(\gamma R-K)-\frac{1-\delta^{2}}{1-\delta}\left(1-\lambda^{k^{*}-1}\right) K\right\}
$$

Noting that condition 7 can be written as

$$
b>(1-\delta)\left(M^{k^{*}}+B^{k^{*}}\right) .
$$

we can see that (8) always holds when (7) is violated so that there will be no delay in period $N-2$ if there is none in period $N-1$.

For earlier periods $N-l$ with $l>2$ we can prove the same result by induction. Suppose the game is in period $N-l$ with $l>2$ and the players hold the belief $\lambda_{N-l}=\lambda^{k^{*}-l+1}$. If from period $N-l+1$ on the project will be pursued without delay until $\lambda_{N}=\lambda^{k^{*}}$ then the entrepreneur will exert effort given a contract that gives him all the surplus if

$$
b \leq(1-\delta)\left(M^{k^{*}-l+1}+B^{k^{*}-l+1}\right) .
$$


This condition is always fulfilled if (7) is violated and can be rewritten as

$$
b \leq \frac{(1-\delta)\left\{\frac{1-[\delta(1-\gamma)]^{l}}{1-\delta(1-\gamma)} \lambda^{k^{*}-l+1}(\gamma R-K)-\frac{1-\delta^{l}}{1-\delta}\left(1-\lambda^{k^{*}-l+1}\right) K\right\}}{\left[1-\lambda^{k^{*}-l+1}+\lambda^{k^{*}-l+1}(1-\gamma)^{l}\right] \delta^{l}}
$$

Anticipating the effort choice of the entrepreneur the investor will accept any financing contract offer that gives him

$$
I_{N-l+1} \geq \frac{K}{\gamma \lambda^{k-l+1}}
$$

and the entrepreneur will propose

$$
I_{N-l+1}=\frac{K}{\gamma \lambda^{k-l+1}}
$$

at time one.

This proves the only if part of the proposition.

To prove the if part of the proposition the following expression will be useful. Let us denote by $\Pi^{k}\left(0 \leq k \leq k^{*}\right)$ the expected present value of payoffs (monetary and private) to the entrepreneur if the project, which is thought to be of good quality with probability $\lambda^{k}$, is pursued without delay as long as $\lambda_{t} \geq \lambda^{k^{*}}$.

Suppose, we are in period $N-l, l \geq 0$ and a financing contract $I_{N-l}=\frac{K}{\gamma \lambda_{N-l}}$ has been accepted and the entrepreneur has to decide whether to exert effort or not. If in the continuation equilibrium after exerting effort without success there will neither be financing nor effort in the next period $(N-l+1)$, the continuation payoff from effort for the entrepreneur from period $N-l+2$ on will be $\Pi^{k+1}$. The expected payoff from exerting effort in period $N-1$ to the entrepreneur is 
then

$$
b+\gamma \lambda^{k}(R+B)-K+\delta 0+\delta^{2}\left(1-\gamma \lambda^{k}\right) \Pi^{k+1} .
$$

If in the continuation equilibrium after shirking the project will be efficiently implemented and the whole surplus will go to the entrepreneur, the continuation payoff for the entrepreneur from period $N-l+2$ on will again be $\Pi^{k+1}$. The expected payoff of shirking to the entrepreneur is then in period $N-l$

$$
b+\delta\left(b+\gamma \lambda^{k}(R+B)-K\right)+\delta^{2}\left(1-\gamma \lambda^{k}\right) \Pi^{k+1} .
$$

Hence, the entrepreneur will not exert effort in period $N-l$ if

$$
b>\frac{1-\delta}{\left(1-\gamma \lambda_{N-l}\right) \delta}\left(\gamma \lambda_{N-l} R-K\right)
$$

Given what we know about equilibrium play in period $N-1$ if (7) holds we can now work backwards. If (10) holds for $\lambda_{N-2}=\lambda^{k^{*}-1}$ the project will delayed in period $N-2$ and then implemented efficiently from period $N-1$ on. A similar argument can be made for any period $N-l, l>2$ and beliefs $\lambda_{N-l}=\lambda^{k^{*}-l+1}$.

We have shown that if the project has not been delayed it will be delayed in the first period in which (10) holds. After this delay it will be implemented efficiently. Therefore, if (10) holds for $\lambda^{0}$ then the project will be delayed in the first period and then be implemented efficiently.

However, to complete the characterization of equilibrium play we have to show that the project is not delayed from period one until period $N-l$ if (10) fails to hold the first time for $\lambda_{N-l}<\lambda^{0}$. To do this let us define $\lambda^{\hat{k}}$ as the lowest belief for which (10) does not hold. 
Now suppose, we are in some period $N-l, l \geq 0$ with a belief of $\lambda^{k}, k<\hat{k}$ and a financing contract $I_{N-l}=\frac{K}{\gamma \lambda_{N-l}}$ has been accepted and the entrepreneur has to decide whether to exert effort or not. If she does not exert effort her expected payoff is

$$
\begin{aligned}
\Pi^{N E} & =b+\delta\left[M^{k}+B^{k}\right] \\
& =b+\delta\left[M^{k}-\delta^{\hat{k}+1-k} M^{\hat{k}+1}+\delta^{\hat{k}+1-k} M^{\hat{k}+1}+B^{k}-\delta^{\hat{k}+1-k} B^{\hat{k}+1}+\delta^{\hat{k}+1-k} B^{\hat{k}+1}\right] .
\end{aligned}
$$

If she does exert effort her expected payoff is

$$
\Pi^{E}=M^{k}-\delta^{\hat{k}+1-k} M^{\hat{k}+1}+\delta^{\hat{k}+2-k} M^{\hat{k}+1}+B^{k}-\delta^{\hat{k}+1-k} B^{\hat{k}+1}+\delta^{\hat{k}+2-k} B^{\hat{k}+1} .
$$

And she does exert effort if

$$
b \leq(1-\delta)\left[M^{k}-\delta^{\hat{k}-k+1} M^{\hat{k}+1}+B^{k}-\delta^{\hat{k}-k+1} B^{\hat{k}+1}\right]
$$

We can rewrite condition 10 for $\lambda_{N-l}=\lambda^{\hat{k}}$ so that

$$
b>(1-\delta)\left[M^{\hat{k}}-\delta M^{\hat{k}+1}+B^{\hat{k}}-\delta B^{\hat{k}+1}\right]
$$

holds.

We have defined $\hat{k}$ so that (12) is violated from which follows that (11) holds for any $k<\hat{k}$. This proves that the entrepreneur has no incentive to shirk in any period $N-l$.

In a nutshell if condition 7 holds the project will be delayed in exactly one period that can be determined by the algorithm above. This proves the if part of the proposition. $\|$ 


\section{Proof of Proposition 2}

Let $\lambda_{t}^{V}$ be the belief of a newly entering venture capitalist in period $t$. In period $N$ the entrepreneur will always exert effort because in case of success she gets $B$ and $E_{N}$ the latter being weakly positive due to the wealth constraint of the entrepreneur. Anticipating this the venture capitalist will accept any contract with $I_{N} \geq \hat{I}_{N}=\frac{K}{\gamma \lambda_{N}^{V}}$. As long as $\lambda_{N}^{V} \geq \lambda^{*}$ this implies $E_{N} \geq 0$ and the entrepreneur will propose a contract with $\hat{I}_{N}$. Otherwise there is no investment.

Let $\lambda_{t}^{E}$ be the belief of the entrepreneur in period $t$. In period $N-1$ the entrepreneur will always exert effort as long as $E_{N-1} \geq 0$ because the refinancing decision and, therefore the expected payoff, in period $N$ does not depend on the effort choice in period $N-1$. If she anticipates that there will not be investment in period $N$ by exerting effort she gets an expected payoff of $b+\gamma \lambda_{N-1}^{E}\left(E_{N-1}+B\right)$ which is larger than $b$, the payoff from shirking.

If she anticipates investment in period $N$ it is still better to exert effort. Exerting effort gives a payoff of

$$
b+\left[\gamma \lambda_{N-1}^{E}\left(E_{N-1}+B\right)\right]+\left(1-\gamma \lambda_{N-1}^{E}\right) \delta\left[b+\gamma \lambda_{N}^{E}\left(E_{N}+B\right)\right]
$$

while no effort leads to

$$
b+\delta\left[b+\gamma \lambda_{N}^{E}\left(E_{N}+B\right)\right]
$$

which is smaller.

A similar argument holds for all periods. Hence, in all periods it is a dominant strategy for the entrepreneur to exert effort if there has been investment. 
Therefore, the venture capitalist will invest in every period $t$ in which $\lambda_{t}^{V} \geq \lambda^{*}$, the entrepreneur exerts effort and gets the whole surplus. The only sequence of beliefs for the venture capitalist that is consistent with these strategies is $\left\{\lambda^{k}\right\}_{0}^{k^{*}}$. With these beliefs there will be investment and effort in the first $k^{*}=N-1$ periods and no investment thereafter. This is the first best.\| 


\section{References}

Bergemann, Dirk, and Ulrich Hege, 2002, The Financing of Innovation: Learning and Stopping, Mimeo Yale University.

Berglöf, Erik, 1994, A Control Theory of Venture Capital Finance, Journal of Law, Economics and Organization 10, 247-267.

Clayton, James, Bradley Gambill, and Douglas Harned, 1999, The Curse of too much Capital: Building New Businesses in Large Corporations, McKinsey Quarterly pp. 48-59.

Cornelli, Francesca, and Oved Yosha, 2003, Stage Financing and the Role of Convertible Securities, Review of Economic Studies 70, 1-32.

Cremér, Jacques, 1995, Arm's Length Relationships, Quarterly Journal of Economics 110, 275-295.

Dewatripont, Mathias, and Eric Maskin, 1995, Credit and Efficiency in Centralized and Decentralized Economies, Review of Economic Studies 62, 541-555.

Gebhardt, Georg, 2001, Venture Capital and Innovation, Mimeo, University of Munich.

Gompers, Paul A., 1995, Optimal Investment, Monitoring, and the Staging of Venture Capital, Journal of Finance 50, 1461-1489. 
Gompers, Paul A., and Josh Lerner, 1996, The Use of Covenants: An Analysis of Venture Partnership Agreements, Journal of Law and Economics 39, 463-498.

Gompers, Paul A., and Josh Lerner, 1999a, An Analysis of Compensation in the U.S. Venture Capital Partnership, Journal of Financial Economics 51, 3-44.

Gompers, Paul A., and Josh Lerner, 1999b, The Venture Capital Cycle. (MIT Press Cambridge, Masachussetts).

Hellmann, Thomas F., 1998, The Allocation of Control Rights in Venture Capital Contracts, Rand Journal of Economics 29, 57-76.

Inderst, Roman, and Felix Muennich, 2001, The Benefits of Shallow Pockets, Mimeo, LSE Financila Markets Group.

Kornai, Janos, 1979, Resource-Constrained versus Demand-Constrained Systems, Econometrica 47, 801-819.

Lerner, Josh, 1994, The Syndication of Venture Capital Investments, Financial Management 23, 16-27.

Maskin, Eric, 1999, Recent Theoretical Work on the Soft Budget Constraint, American Economic Review 89, 421-443.

Neher, Darwin V., 1999, Staged Financing: An Agency Perspective, Review of Economic Studies 66, 255-274. 
Sahlman, William A., 1990, The Structure and Governance of Venture-Capital Organizations, Journal of Financial Economics 27, 473-521.

Schmidt, Klaus M., 1996, The Costs and Benefits of Privatization: An Incomplete Contracts Approach, Journal of Law, Economics and Organization 12, 1-24.

Schmidt, Klaus M., 2003, Convertible Securities and Venture Capital Finance, Journal of Finance 58, 1139-1166. 